\title{
PLANNING OF HUMAN ACTIVITIES BASED ON THE VIEWS OF LOCAL AUTHORITIES IN PROTECTED AREAS: THE CASE OF MOUNTAIN PELION, GREECE
}

\author{
O. CHRISTOPOULOU \& E. TRIZONI \\ Department of Planning and Regional Development, University of Thessaly, Greece.
}

\begin{abstract}
The subject of this paper is the research into the opinions of the local authorities in the region of Pelion, which is a part of the Natura 2000 network of protected areas, with regard to zoning and planning in the region. In particular, the objectives of the present research are: local authorities' views on current planning and zoning (positive and negative), and on theories for future planning and zoning and the desirability/undesirability of their outcomes; the problems (developmental, environmental and social problems concerning the implementation of Natura 2000) faced in the area; the targets local communities would like to see accomplished by Natura 2000 and their suggestions on how these targets could be achieved; and how to solve local problems. The findings and the conclusions of this research reveal a conflict between policymakers and local communities. Much closer collaboration between the two is required before any long-term policy of development can have any chance of success. From this research it was found that local authorities propose: (a) zoning with moderate levels of protection, (b) terms and conditions of protection which focus on hunting and tree-felling and (c) mixed management teams (European, state and local agents.)
\end{abstract}

Keywords: local authorities, protected areas, zoning.

\section{INTRODUCTION}

The fairly recent enhancement of fundamental planning (economic effectiveness, environmental protection) with the principle of social justice forms the basis for assessing the success of applied policies internationally: high success rates are recorded when policies take into consideration the socio-economic aspects of an area than when such factors are ignored.

Consequently, the close cooperation with local communities (there is a coincidence between local communities' and local authorities' views, as explained in Section 3) for the design and implementation of the measures recommended is, according to international experience, essential. The inclusion of the collective experience of the local population in environmental management increases the possibility of successful planning and implementation of environmental protection policies, whereas the exclusion of local communities can result in the problematic environmental management of a region [1]. Problems may arise in the form of frequent violations of regulations, disregard for the environment, abandonment of rural areas, and generally a negative response among local communities to every attempt to implement policies aimed at environmental protection [2]. Moreover, strictly rational-scientific approaches often result in the introduction of rules and/or restrictions that are problematic in their implementation because they are particularly harsh and inflexible. Empirical evidence dictates that such legislation yields exactly the opposite results from those it was designed to achieve $[3,4]$, particularly so when the local community has not consented to the rules they are expected to abide by.

In order for local communities to participate in a meaningful way, it is not enough simply to record their views on the planning, zoning and management of the area. Successful planning must recognise the existence of local opinion and not simply make assumptions about what local opinion will be. Local communities cannot be expected to formulate viewpoints unless they are fully informed regarding proposals, implementation methods, policy aims, recommended methods of protection 
and possible ways of managing the region. Only in this way can the foundations of meaningful dialogue be laid down and the possibility of the introduction (and enforcement) of unjust policies be avoided.

\section{RESEARCH AREA}

The research area is the region of Pelion, site GR1430001 of the Natura 2000 network (Fig. (1). The areas of Natura 2000 comprise a network of ecological sites which, due to their specific characteristics and diversity of vegetation, are judged to be important in the conservation of wild flora and fauna [5]. The inclusion of the Pelion region was carried out under Article 3 of Guide 92/43/EEC - European Committee, which envisages the creation of a European Ecological Network of Distinct Conservation Zones.

The region covered by this research includes sections of, or in some cases the entire area of, nine local authorities: Milies, Zagora, Makrinitsa, Artemida, Portaria, Keramidi, Mouresi, Agria and Afetes. In order for the findings of this research to be put into context, knowledge of its major physical, political, social and economical characteristics is required $[6,7]$. The region is of major ecological value and contains a wide range of biotopes which current communities support substantially and, as a consequence, the level of conservation ranges between good and excellent; the economic value of the region is based on four principal revenue generating sectors: agricultural cultivation (arboriculture, especially olives and apples, and horticulture), tourism and of smaller importance livestock farming and timber production; moreover, the region is an area of unique natural beauty due to the harmonisation of local building styles with the natural environment.

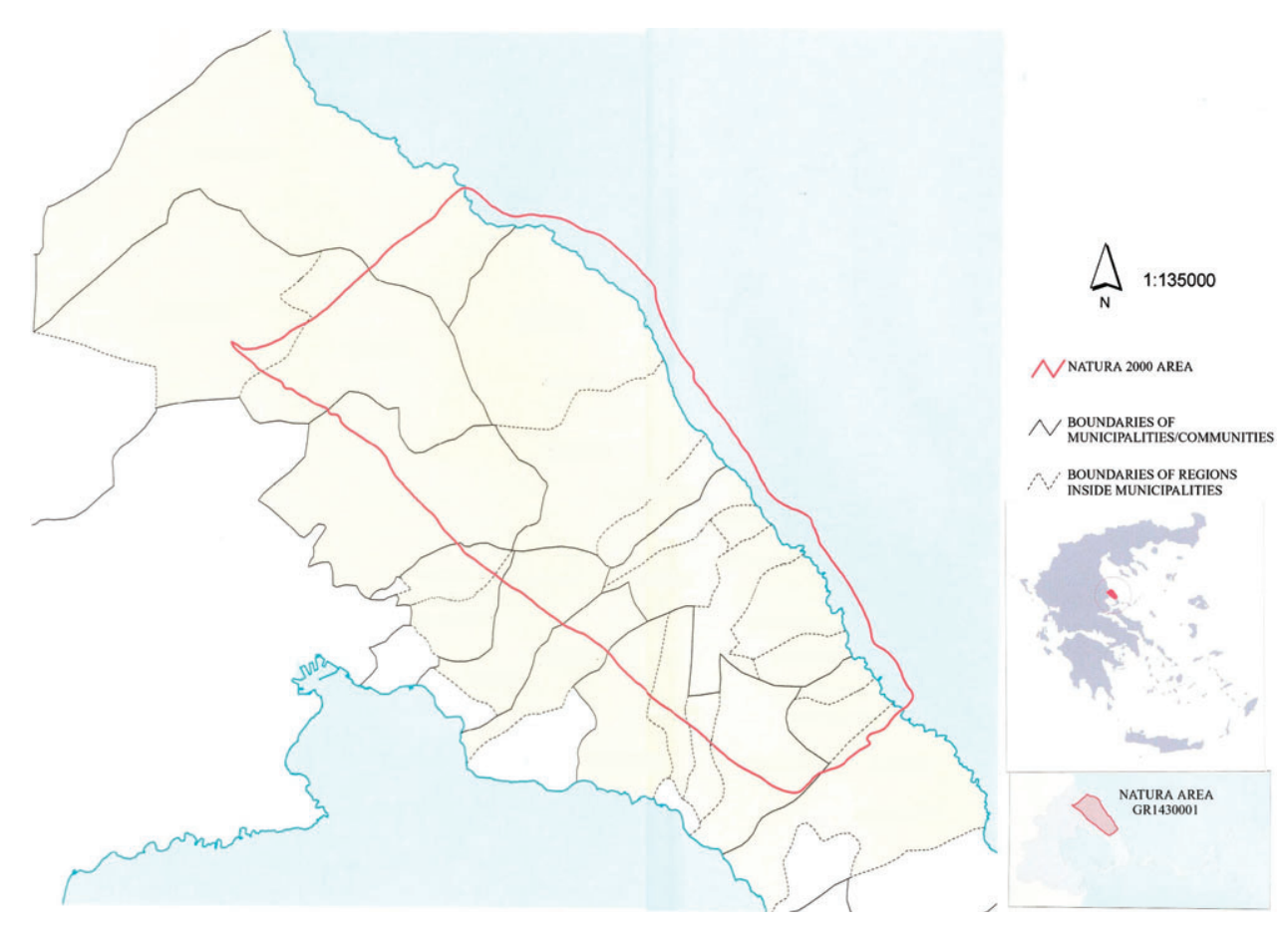

Figure 1: The research area: boundaries of the Natura 2000 area of Pelion. 


\section{METHODOLOGY}

The research was carried out by conducting personal interviews of local authorities' representatives. The decision to interview local authorities' representatives instead of people from the local communities was based on the results of an earlier research in the same area [8] and because of the absence of an administration agent. The earlier research showed that $86.1 \%$ of the local people were not aware that the area was included in some form of protection programme, $89.7 \%$ were not aware of which areas were covered by the 'Natura 2000' network and $84.4 \%$ were not aware of the aims of 'Natura $2000^{\prime}$.

In the framework of the two projects - (a) awareness actions for the implementation of Directive 92/43/EC concerning the protection of natural habitats as well as wild fauna and flora in Central Greece (EU 2002-04); (b) local communities' awareness with respect to the protection and the possibilities of sustainable development of the Natura 2000 site: Mountain Pelion and coastal/marine zone (Ministry of Environment 2003-04) - that followed the above research, there was a familiarisation of the local people with the aims of the Natura 2000 network, given that an administration agent was still missing. Throughout the contacts with local authorities and residents of the wider area, which took place during these projects and on the occasion of congresses, meetings and seminars ( 1 congress: 26/4/2002, in the presence of authorities and scientists; 1 workshop: 28/3/2003, in the presence of authorities; 1 congress: International Congress on Management Plans and Boards of Natura 2000 sites, in collaboration with Observatory Juridical, 19 and 20/3/2003, Pelion; 2 meetings: 6/6/2003, 9/2003, in the presence of authorities and stakeholders; 1 seminar: 19/6/2003, in the presence of authorities and stakeholders; 1 seminar: 4/11/2003, in the presence of authorities), a coincidence between local authorities' and local communities' views was observed, which allowed the selection of local authorities to answer the questions of this research (as they represent their communities' views).

Therefore, based on the coincidence of local communities' and local authorities' views, we selected a methodology that was not based on the method of representative sampling of residents but based on the method of 'open' interviews, using a questionnaire as a base (see Appendix) on a focus group, which in our case consisted of local authorities from the Natura 2000 region. The aim of this research was not the quantification of local communities' views but the enlightenment of their problems and, more importantly, the enlightenment of their needs for a management that incorporates their views and, as it is known, an approach through 'open' interviews allows the analysis of data appropriate for the collection of qualitative information. [9]

The interviews were conducted mainly in the form of a discussion that arose from issues raised by the questionnaire devised for purposes of the research. The questionnaire itself followed the conventional question-answer format.

The questionnaire consisted of 11 questions some of which had more than one component. The majority of questions were designed in such a manner so as to encourage open responses from interviewees while at the same time discouraging irrelevant responses. In some cases, respondents were required to indicate their views on the issues raised by the question (agree/disagree, benefits/ consequences) while other questions required respondents' comments on existing problems (both in general terms and in connection with the region's inclusion in the network). The responses to the questionnaire and the wider discussion of the matters in question were used to formulate a policy for the protection and administration of the protected area.

\section{FINDINGS}

The views of the representatives of local authorities are summarised below. They are arranged according to the frequency of responses and range from the highest number of responses to the lowest. 


\subsection{Positive outcomes}

Local authorities report as probable positive outcomes:

(a) The expedition of protection measures for forest areas in the region (designation of fire zones, design and implementation of a management system, setting of limits on activities within the timber industry).

(b) The development of tourism (increase and improvement of existing tourism services).

(c) The modernisation of water supply and sewage treatment infrastructure (increased capacity; replacement of aged, environmentally unfriendly methods with new methods that do not harm the environment).

These issues were seen to be positive by three local authorities. The main issue raised concerns the establishment of measures to protect the forests of the region. Of the remaining six local authorities, four did not give positive responses, the representative of one authority commented that he was not sufficiently informed to be able to respond to the question and another felt that there was nothing to be gained by the inclusion of his region in the Natura 2000 network.

\subsection{Negative outcomes}

Local authorities assess as probable negative outcomes:

(a) The retardation of local development which may be induced by various factors such as: the increased complexity of the procedures for granting permits for developmental projects, the increased costs incurred for the implementation of projects that require the submission of an environmental impact assessment, the increased costs incurred by local authorities for the implementation of protection measures and of development projects with specific environmental prescriptions, the imposition of additional (environmental) restrictions on projects, the loss of funding opportunities from European programmes due to the complexity of the application process, little and inaccurate information concerning the exact borders of the area included in the Natura 2000 network, lack of clarity concerning what exactly is permitted and what is prohibited in the realisation of scheduled projects, and lack of alternative proposals for more appropriate solutions to local problems as well as local development within the Natura 2000 network.

(b) The reduction in tourism which may arise either due to possible limitations to tourist activity, resulting in the need for alternative sources of employment, or due to the abolition of management of private areas characterised as woodland zones.

Seven local authorities reported negative outcomes. The most prominent response refers to the retardation of development projects, and the main reason given for this is the increased complexity of the procedures involved in the permit for the implementation and the increased costs incurred by such projects. The remaining two local authorities made no reference to negative outcomes as they felt that there were no negative outcomes in the particular sections raised in the questionnaire.

\subsection{Desirable outcomes}

Desirable outcomes are defined as the expected (but not existing) outcomes. Local authorities that fall within the institutional framework that will govern the particular region, expect:

(a) The protection and improvement of the environment, which is expected to be achieved as a result of the construction of log cabins for visitors, effective controls on building construction, 
the elimination of certain sources of pollution (e.g. pig sties), and the effective control of new road construction within residential and woodland areas.

(b) Reduction in illegal activities (illegal hunting, timber harvesting, fishing and building construction) as a result of tight controls on timber harvesting and fishing, the establishment of a network of gamekeepers, and the introduction of effective measures to control building construction.

(c) Attraction of 'quality' tourism that is expected to be achieved as a result of the anticipated restoration, maintenance and exploitation of the natural beauty of the area and the introduction of new leisure activities to the area - such as horseback riding, climbing, health tourism - the upgrade of climbing/walking routes and the investment in accompanying infrastructures.

(d) An increase in the income of residents as a result of either the expansion of the tourist industry, resulting in the increase in the number of local residents employed in the sector, or the consolidation of biological farming methods, resulting in increased crop yields, nullification of the cost of fertiliser and pesticide application and, ultimately, the increase in net profits to the farmer.

(e) Protection of the natural environment due to the opportunities for the promotion of alternative forms of tourism that will contribute to increased awareness of the environment, the widespread use of biological farming methods, and the establishment of permanent strictly controlled and monitored hunting grounds.

(f) Improvements to the quality of infrastructure, services and products due to the establishment of a system of quality certification for products and services (local products, accommodation, etc.) and the setting of the pre-requisites for the attraction of 'quality' tourism (improvements in infrastructure, transportation, communications).

(g) Granting the right for mild interventions in protected areas which are inhabited.

(h) Increase in the percentage of livestock farming.

Desirable outcomes were registered by all the local authorities questioned. The most significant desirable outcome of the implementation of Natura 2000 policies was considered the protection and improvement of the environment in the area. An intensive desire for the reduction in illegal activity and the attraction of 'quality' tourism was expressed. Other local authorities felt an increase in the income of the local residents to be equally important to the protection of the environment, and to a smaller extent the improvement to infrastructure, services and products; of still smaller significance, the granting of rights for mild intervention in inhabited conservation areas and the increase in livestock farming were reported.

\subsection{Undesirable outcomes}

The interviewees expressed the scepticism that the inclusion of their area in the Natura 2000 network would induce undesirable outcomes such as:

(a) The possible introduction of further restrictions on the management of resources (forests, land and tourism) as a result of the prohibition of the total exploitation of forests (collection and trade of fallen trees); the prohibition of independent management of agricultural/farming privately owned lands, a right granted by the present framework; the limits set to restrict the development of tourism (restriction on building tourist facilities of high capacity); the introduction of stricter building regulations; and the changes in the methods of forest conservation.

(b) The reduction in the population in mountain areas. It is believed that this undesirable outcome will arise as a result of the restrictions in the use of the current road network (it was felt that this would seriously damage farming activities); the non-granting of financial aid to implement the anticipated environmental requirements for future road networks; the lack of alternative 
types of occupation; and the absolute retraction of projects vital for the development of certain areas.

(c) The anticipated introduction of limitations to or prohibition of hunting.

(d) The anticipated prohibition of economic activity in the protected woodland areas (timber, earthwork).

(e) The anticipated interference in private landowners' affairs.

(f) The anticipated enforcement of the transition from traditional farming methods to ecologicalbiological methods.

Five local authorities reported undesirable outcomes. The main undesirable outcome was considered the introduction of further restrictions in the management of resources. Serious concern that the new framework would lead to a reduction of the population in the area was expressed by the respondents, as well as the undesirability of limitations to or prohibition of hunting in the area. Smaller concern was reported about the possible restrictions on logging and earth removal, the interference in private landowners' matters, and the enforced transition from traditional to ecological agriculture. The remaining local authorities did not make any reference to undesirable outcomes nor did they express anxiety about any of these issues.

\subsection{Problems}

According to the interviewees, all the local authorities that come under the Natura 2000 network face problems that are concerned with development, the environment, the social conditions and the implementation of the policy that governs the Natura 2000 framework.

4.5.1 Development problems

(a) The insufficient technical and social infrastructure: This is considered the most important problem faced by the local authorities in the region. Interviewees mention in particular the shortage of health and education infrastructure resulting from the lack of funding by the relevant ministries; the delay in the payment of funds (to date only 30-40\% of the funds allocated by the Special Local Support Programme to the area have been paid); shortages in the capacity of water supply; aged sewage systems; the poor condition of the primary and rural road networks.

(b) The intensification of agriculture: This has led to a reduction in agricultural production, which in turn has caused the shrinkage of the agricultural income, the shrinkage of the agricultural sector and at the same time the expansion of the tertiary sector. The transition from agricultural to residential land use is a manifestation of the shrinkage of the primary sector.

(c) The prevailing sense of insecurity felt by investors due to the inaccuracies concerning the permissible within the Natura 2000 network activities and projects: This leads, according to local authorities, to stagnation of investments in the region.

4.5.2 Environmental problems

The environmental problems reported concern:

(a) The changes in the appearance of the landscape due to the incompatibility with the feel of the area's residential activities.

(b) The pollution of surface and underground waters due to the use of asbestos in the construction of sewage pipes. 
4.5.3 Social problems

(a) The gradual aging of the population in local municipalities, due to the gradual reduction of young people. The second phenomenon has its roots in the shortage of alternative (to agricultural or livestock production) employment options as well as the parallel decline observed in the agricultural sector.

4.5.4 Problems related to the implementation of the Natura 2000 network policies

Local authorities consider the information given to justify the reasons for the inclusion of the region into the network, about the gains and/or restrictions as a consequence of this as well as the information on the possible financial advantages to local residents, insufficient.

This lack of information is the source of a great deal of negative response to the network which threatens its successful implementation. There is also marked concern about the sufficiency in institutional funds for the implementation of desirable projects. According to the local authorities, the complete deposition of the financial support for the implementation upon the municipalities, which have shortage of funds, jeopardises the successful implementation of Natura 2000. The enactment of the Natura 2000 network is considered an unsolicited imposition of environmental protection. The failure to ensure the local support increases resistance to policies.

\subsection{Proposals from relevant organisations}

The proposals of the local institutions (according to the questionnaires and the broad discussions which took place) concern the targets set for each municipality, the measures needed for the implementation of these targets, the institutional framework and also the proposed zoning. The proposed (desirable) targets concern:

(a) The restoration, preservation and improvement of the quality of the environment with the protection of the biodiversity, the inhibition of the constant decline in bird fauna, the replacement of current aggressive forms of development with milder forms of development, the nullification of any threat to public health from polluted underground water, improvements to the road network which connects the local authorities with the local ski resort, the maintenance of the current satisfactory state of forest areas, and aesthetic improvements in the landscape.

(b) Improvements to the quality of life of residents which may be accomplished by putting an end to the isolation of remote areas, the modernisation of the technical and social infrastructure, and the revitalisation of the hypotonic investment in the area.

(c) Reversing the reserved and negative attitudes of local residents about the incorporation of the region into the Natura 2000 network by the inclusion of local opinion at the planning and implementation stages of Natura 2000 policies; focusing of Natura 2000 policies on local residents as the beneficiaries; the simplification of the procedures for approval or rejection and the subsequent granting of permits for the implementation of scheduled programmes in the areas covered by Natura 2000; the financial support to local authorities. These are some proposals for appeasing the negative public opinion concerning the prospect of being included in the Natura 2000 network, along with the parallel attempts by the state to convince local residents that the environment can be a major development drive.

(d) The sustainable development in the area through the practice of mild forms of tourism (ecotourism, scientific tourism, religious tourism).

(e) Safeguarding the persistence of human presence in the protected area.

(f) Finding a solution to the economic impasse faced by farmers through the eradication of traditional farming methods and shifting the main focus of economic activity to the tertiary sector. 
(g) The identification of the economic and cultural features of the area and their correlation to the prevalent global cultural prototypes. This may be accomplished by the revitalisation of the agricultural sector, according to the model that was prevalent in the area a hundred years ago. Its characteristics will be the production of certain labelled varieties of strictly local agricultural products and the conservation of old local varieties.

(h) The more efficient utilisation of natural resources (forests/water).

(i) The need to compromise conservation and the opportunities presented by the natural environment of the area with the economic and recreation needs of local residents.

(j) Maintaining the younger population in the area.

Targets were reported from all local authorities surveyed. There is a convergence of views with respect to the preservation and improvement of the environment in the area, which, along with the improvement in the quality of life of local residents, was reported to be of major importance.

Local institutions, expressing public opinion, suggest various scenarios concerning the zoning of human activity in the area:

(a) Scenario A

I. Zone A: Absolute conservation zone, includes unexploited tourist coastal areas in which wildlife and its habitats are present.

II. Zone B: Partial conservation, includes all woodlands in the Natura 2000 site of Pelion; it is proposed that controlled timber harvesting and earth removal be continued within zone B.

III. Zone C: Productive activities zone, comprise all the urbanised areas in the Natura 2000 region of Pelion.

(b) Scenario B

I. Zone A: Absolute conservation area, consists of areas that present distinctive biodiversity.

II. Zone B: Mild intervention zone, consists of the areas surrounding the local authorities of Zagora and Mouressi.

The steps proposed for setting the rules and suitable protection methods are: the restriction of the hunting bags, the prohibition of activities that lead to the degradation of the natural environment, the introduction of strict regulations and a system of monitoring timber harvesting activities, and the establishment of a controlled hunting area and hunting check points.

The proposed monitoring of protected areas would be the responsibility of a mixed team comprising

(a) representatives of government agencies, representatives of local authorities, members of local organisations (hunting clubs, hotel owners, business owners, farmers/livestock farmers and specialists);

(b) representatives of local agencies, representatives of the EU and representatives of relevant ministries (Ministry of Agriculture, Ministry of Environment Physical Planning and Public Works);

(c) local representatives (municipal councils, associations, hunting clubs and government agencies).

As evident from above, the suggested scenarios on zoning do not reflect the guidelines of the 'Outline Law on the Environment (1650/86)' and their boundaries are not well defined. In the first case, the features used were selected by local authorities and would promote targets and establish a level of activity that they feel would be advantageous to the areas that fall within each zone. In the second case, zoning does not mainly depend on land divisions but, instead, on certain features (e.g. unexploited coastal areas where rare wildlife species are found, areas that contain distinct biodiversity). It may be inferred that local authorities are neither familiar with the institutional framework of environmental 
protection, nor are they aware of the particular location of land that is characterised by features which are worth protecting.

Clearer opinions are reported regarding the establishment of limits, methods of protection and supervision of zones. The proposed measures are specific and clear and are based on the activities of hunting and timber production, with the ultimate goal of reducing unauthorised activity in these areas.

As far as management of the zones is concerned, there is a convergence of views about the most appropriate method: setting up a mixed team of representatives. The desire of the local authorities for a multi-member, multi-dimensional body is clear. The model for the composition of the management body proposed by most respondents involves the following three levels: the state, the local authorities and the local community. One authority indicated the desire for the participation of a representative of the $\mathrm{EE}$ in the team.

\section{GENERAL CONCLUSIONS}

From the results of the survey it was found that local residents are very receptive to proposals for alternative sources of income, the end to isolation, the protection of the environment in a manner that does not threaten their economic interests and the continued existence of hunting in the region. On the other hand, it was also found that there is significant opposition to the probable prohibition of independent management of property, the reduction or prohibition of timber harvesting and earth removal and the cessation of certain road building or tourism projects.

It is also evident that objections of local authorities/communities are in direct proportion to the size of protected land in their area; the more developed districts objected to a smaller degree than the districts that are less developed; traditional farming methods are at an impasse (reduced quality and quantity of production); and there is considerable dependence on the nearby urban centre of Volos and on the state.

It is worth noting that the viewpoints, principles, aims, objectives and proposals expressed by local authorities/communities are at odds with those expressed by environmental protection bodies (Natura 2000):

\begin{tabular}{ll}
\hline Natura 2000 policies & \multicolumn{1}{c}{ Local communities } \\
\hline - Environmental protection (high priority) & - Protection of local interests (high priority) \\
- Sustainable, long-term development & - Short term - instant profits \\
- European and/or state administration & - Regional and/or local administration \\
- Restriction/prohibition & - Flexible/moderate restriction, no prohibition \\
- Projects approved/rejected by Ministry of & - Projects approved/rejected by regional or \\
Environment Physical Planning and Public & \\
Works & district council \\
\hline
\end{tabular}

In order to mitigate these differences it is necessary to identify the reasons behind them, which can be summarised as follows:

- Local residents do not feel that they are well informed about which activities will be allowed and which will be prohibited.

- The fact that they have neither been consulted about the selection of areas to be protected nor involved in the implementation of protection policies had lead to negative attitudes and distrust.

- The desire for easy (short-term) profits is prevalent in the area which in the long run can be at the expense of the environment. 


\section{PROPOSALS}

Grounds for differences between the aims and objectives of Natura 2000 policies and those of local residents were found to exist on many different levels. Consequently, finding a way of reconciling these is of significant importance; thus, on a general level, policies must be devised that satisfy all parties, and which fulfil the most important aims and objectives of both parties. Because of the extent of the region in question this is not just an option, it is absolutely vital. A method of management-administration must be established that will permanently (or at least in the long term) reconcile existing ideologies and practical differences.

In the setting up of objectives and the establishment of measures and methods of achieving them, it must be borne in mind that rural planning is by its very nature participational and, a priori, social. Flexibility and objectivity are essential to avoid the outcry that will result if rigid legislation is imposed on local communities without prior consultation. Consequently, the successful organisation of human activity, the infrastructure and the urbanisation of the specific area will depend on the level and quality of cooperation with local communities. These two factors are fundamental to the implementation of Natura 2000 policies in Greece. Furthermore, great significance is placed on convincing local communities that the consequences of unplanned development in their area will have a negative effect on the potential for future development.

The objectives that follow are based on a system of ideals the basis of which is the aim of sustainability: social justice, economic efficiency and environmental protection. This system is based on a number of general conditions, namely:

(a) Proper management of natural resources: The incorporation of environmental factors and common demands for sustainable development.

(b) Successful spatial socio-economic cohesion: Balanced regional development within an integrated planning; connection of developmental and regional and rural planning strategies; equal opportunities throughout the regions; equal participation of all bodies within the geographical area in all policies and their implementation; inclusion of viewpoints and briefing.

Objectives specific to the area covered by the research:

(a) Maintenance of the notable natural and cultural environment of the area.

(b) Restoration (where it is considered essential) and maintenance of the harmony between people and nature.

(c) Sustainable administration of the objectives of the local, natural and cultural environment: land cultivation, fishing, mineral wealth, wildlife, forests, cultural monuments and characteristics.

(d) Decrease of the dependence of the local authorities in the region on the urban centre of Volos, with the main aim of establishing a way of maintaining current population levels and attracting more residents.

(e) Speeding up procedures for local authorities in the region. This is dependent on the speeding up of the procedure for evaluating environmental assessments of projects within the Natura 2000 region.

(f) Retrieval of the primary and secondary sectors' specificity in the region. At the same time, a new area of expertise must be developed, which is both appropriate to the area and in the tertiary sector.

(g) Economic dependence of residents on the quality of the environment.

(h) Elimination of the exclusion of certain areas from the total developmental progress of the remainder (e.g. the district of Keramidi).

(i) Economic autonomy of all local authorities within the region.

(j) Ensuring continued human presence in the entire region. The intention of human activities should be determined by the physical characteristics of the locality in question. 


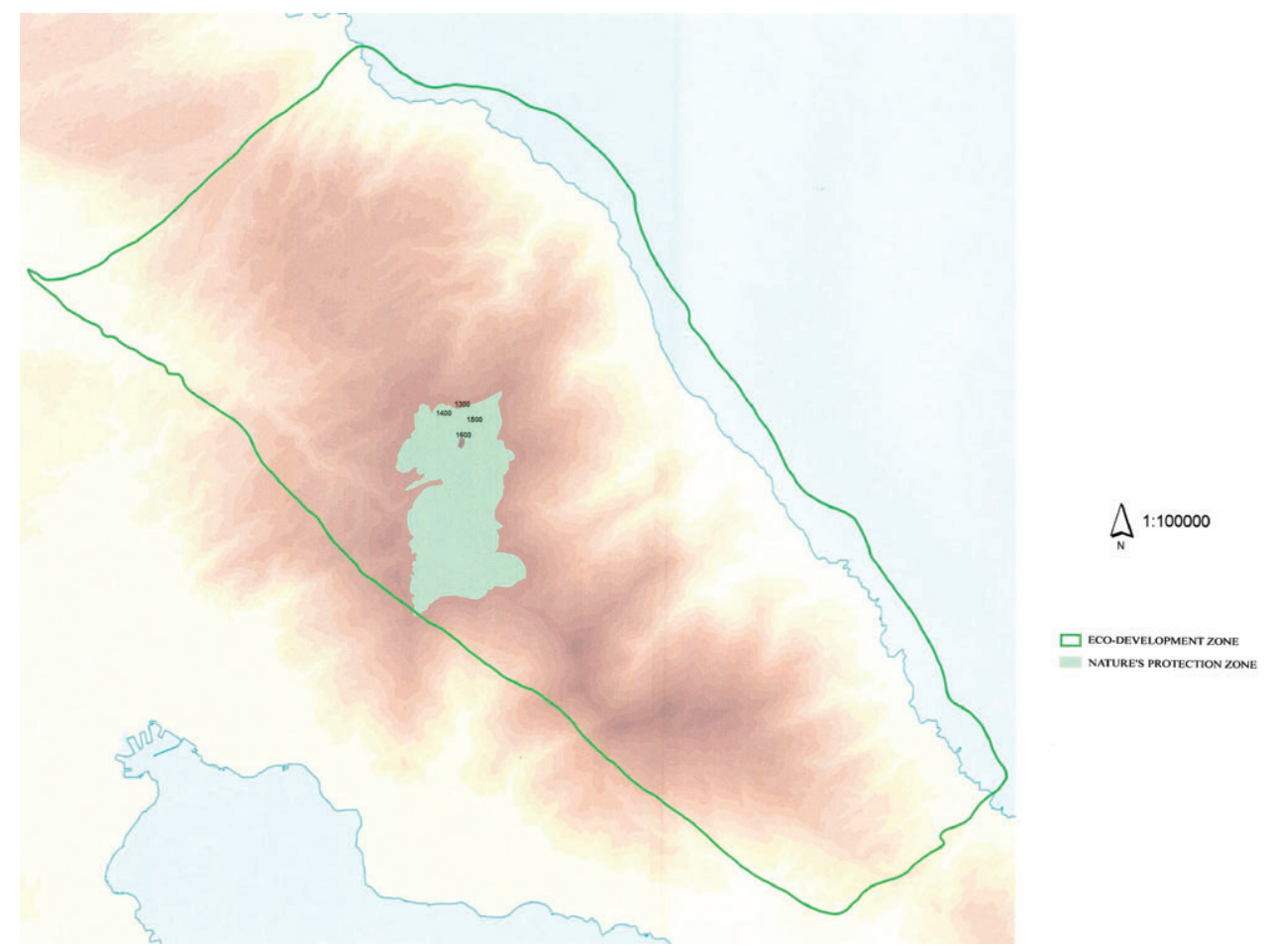

Figure 2: The study area: levels of conservation.

(k) Inclusion of local viewpoints in the planning and implementation of Natura 2000 policies. The main aim here is the effective implementation of Natura 2000 policies and a reduction in the opposition of local communities to the incorporation of their district into the network.

(1) Observance of tourist carrying capacity within the area.

(m) Landscape improvements.

For the attainment of goals $a$ and $b$, it is recommended that zones of differing levels of conservation be established (Fig. 2), taking into consideration environmental legislation (Outline Law on the Environment 1650/86):

Zone A: Ecodevelopment. This zone includes all the area within the boundaries of the Natura 2000 region. It is recommended that the level of protection follows the terms and conditions set out in the legislation (Outline Law) governing 'Areas of ecodevelopment'. The boundaries of the zone are formed by a number of ecosystems which contain types of natural flora and fauna species that have been recorded, evaluated and mapped according to Directive 92/43/EEC. The total area of the housing development zone is equivalent to approximately 32,080 ha.

Zone B: Zone for the Protection of Nature. This zone consists of a distinct finger-shaped area of land, the inner limits of which correspond with the boundaries of the military installations located at 'Pourianos Stavros' and the outer limits of which is the altitude of $1300 \mathrm{~m}$. The type of protection recommended is that established under the terms of the legislation governing 'Areas for the protection of nature'. The total area of land in this zone is equivalent to approximately 1600 ha. 


\section{REFERENCES}

[1] Faust, B. \& Smardon, R., Introduction and overview: environmental knowledge, rights and ethics: co-managing with communities. Environmental Science and Policy, 4, pp. 147-151, 2001.

[2] Bess, R., New Zealand's indigenous people and their claims to fisheries resources. Marine Policy, 25, pp. 23-32, 2001.

[3] Songorwa, A., Community-based wildlife management (CWM) in Tanzania: are the communities interested? World Development, 27(12), pp. 2061-2079, 1999.

[4] Castro, A. \& Nielsen, E., Indigenous people and co-management: implications for conflict management. Environmental Science and Policy, 4, pp. 229-239, 2001.

[5] European Committee, Natura 2000 - Managing our Inheritance, Information Leaflet, European Community Department of Academic Publications: Luxemburg, 1998.

[6] Vabizos, G., Zannaki, K, Zafeiropoulos, D. et al., Specialised Environmental Study of the Peninsulas of Magnesia, Volos (in Greek), University of Thessaly Department of Planning and Regional Development, 1996.

[7] Christopoulou, O., Production activities in the 'Natura 2000' region of Pelion (in Greek). Development Issues the 'Natura 2000' Region of Pelion, Conference presentation, 7 July 2003.

[8] Christopoulou, O., Network NATURA 2000: Awareness and attitudes of mountain people (the case of a Greek mountain). XVI AESOP Congress, Planning in Border Regions, 10-15 July, Volos, Greece, 2002.

[9] Duquenne, M.N., ed., Local specificities - local dynamics: guide for its investigation (in Greek), act III, University of Thessaly, p. 108.

\section{APPENDIX \\ QUESTIONNAIRE}

1) Do you agree with the incorporation of the region covered by your local authority to the Network 'Natura 2000'?

$\square$ Yes

Because

No

Because.

2) What are the gains (potential) negative consequences of this?

Gains:

Consequences:

3) What projects have you scheduled for your district for the period 2000-06; which programmes are sponsoring each of these projects?

a. Projects already completed:

Sponsor: ...

Funded by:

b. Projects to be undertaken (which have been proposed and approved):

Sponsor:

Funded by:

c. Proposed projects (proposals have been submitted. Awaiting final decision regarding acceptance/rejection):

d. Planned projects (not yet proposed, under discussion):

4) Do you believe that the Network and the above-mentioned projects are?

a. Completely compatible 
b. Partially compatible $\square$

c. Totally incompatible

5) Will inclusion into the Network affect the management/exploitation of forests and in what way?

$\square$ Yes

No

6) Agriculture/livestock farming in your region is mainly:
a. Intensive
proportion
b. Arbitrary $\square$
proportion
c. Biological
proportion.........

7) a. Are there any mines/quarries in your local authority?
$\square$ Yes
$\square \quad$ No

b. Do you believe that the characteristics of this type of economic activity are compatible with conservation prescribed by Natura 2000? If yes, under what (potential) circumstances? If no, why?

$\square$ Yes

No

8) Do you believe that hunting helps the development of the area (by increasing the number of visitors) or does it simply harm animal populations?

9) Do you believe that inclusion into to Network will?
a. Be of benefit to tourism in your area.
b. Lead to a reduction in tourism.
c. Have no effect whatsoever on tourism.

10) What in your view are the most significant problems faced by your district (please respond according to the extent of each problem in each of the following categories):

- developmental

- environmental

- social

- other

11) What are your views on current and potential problems, what are your goals and what measures to you propose for the solution of those problems and the achievement of those goals?

a. Views on problems and outline of goals:
i. on a regional level
ii. on a local authority level
iii. on a community level

b. Proposed measures for the achievement of goals and the solution to problems:

i. on a regional level

ii. on a local authority level

iii. on a community level

c. Potential institutional framework

d. Recommended method of supervising zones. 